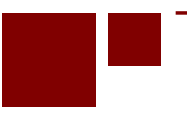

C E N T E R for RETIREMENT RE S E A R C H at BOSTON COLLEGE

\title{
SCHEDULING UNCERTAINTY AND EMPLOYMENT OF YOUNG ADULTS WITH DISABILITIES
}

\author{
Dara Lee Luca and Purvi Sevak \\ CRR WP 2020-5 \\ January 2020
Center for Retirement Research at Boston College Hovey House 140 Commonwealth Avenue
Chestnut Hill, MA 02467 \\ Tel: 617-552-1762 Fax: 617-552-0191 \\ https://crr.bc.edu
}

Dara Lee Luca is an adjunct lecturer in public policy at Harvard University and a researcher at Mathematica - Center for Studying Disability Policy (CSDP). Purvi Sevak is a senior researcher at Mathematica-CSDP. The research reported herein was derived in whole or in part from research activities performed pursuant to a grant from the U.S. Social Security Administration (SSA) funded as part of the Retirement and Disability Research Consortium. The opinions and conclusions expressed are solely those of the authors and do not represent the opinions or policy of SSA, any agency of the federal government, Mathematica-CSDP, or Boston College.

Neither the United States Government nor any agency thereof, nor any of their employees, make any warranty, express or implied, or assumes any legal liability or responsibility for the accuracy, completeness, or usefulness of the contents of this report. Reference herein to any specific commercial product, process or service by trade name, trademark, manufacturer, or otherwise does not necessarily constitute or imply endorsement, recommendation or favoring by the United States Government or any agency thereof.

(C) 2020, Dara Lee Luca and Purvi Sevak. All rights reserved. Short sections of text, not to exceed two paragraphs, may be quoted without explicit permission provided that full credit, including (C) notice, is given to the source. 


\begin{abstract}
About the Center for Retirement Research
The Center for Retirement Research at Boston College, part of a consortium that includes parallel centers at the National Bureau of Economic Research, the University of Michigan, and the University of Wisconsin-Madison, was established in 1998 through a grant from the U.S. Social Security Administration. The Center's mission is to produce first-class research and forge a strong link between the academic community and decision-makers in the public and private sectors around an issue of critical importance to the nation's future. To achieve this mission, the Center sponsors a wide variety of research projects, transmits new findings to a broad audience, trains new scholars, and broadens access to valuable data sources.
\end{abstract}

Center for Retirement Research at Boston College

Hovey House

140 Commonwealth Ave

Chestnut Hill, MA 02467

Tel: 617-552-1762 Fax: 617-552-0191

https://crr.bc.edu

Affiliated Institutions:

The Brookings Institution

Mathematica - Center for Studying Disability Policy

Syracuse University

Urban Institute 


\begin{abstract}
This paper examines the prevalence of scheduling uncertainty and the degree of work hour volatility among young adults with disabilities from 2008 through 2018, using data from the Current Population Survey and the National Longitudinal Youth Survey. First, the paper documents the magnitude of several features of irregular schedules among workers with disabilities in recent years. Second, it examines differences in irregular schedules between workers with and without disabilities. Third, it describes the trends in these features over the past decade. A key limitation of the study is that it cannot directly measure whether workers are employed in gig jobs.
\end{abstract}

The paper found that:

- Young adults with disabilities are more likely to report having irregular work schedules and experience higher volatility in month-to-month work hours compared to their peers without disabilities.

- The percentages of youth who report varying work hours or irregular schedules have decreased slightly over the past decade.

- Trends in work hour volatility have remained stable over the past decade for youth with and without disabilities.

The policy implications of the findings are:

- The increased availability of gig jobs in recent years might make it easier for adults with disabilities to work. To the extent this is true, an increase in gig jobs could lead to higher employment rates among workers with disabilities.

- However, the day-to-day unpredictability in these jobs could present different challenges, especially for workers who need accommodations.

- Although the results in this study do not provide evidence of increased hours volatility on average across workers, future research with improved data on job categorization could explore more directly the potential benefits and risks of gig economy jobs for people with disabilities. 


\section{Introduction}

Researchers have documented increases in household income volatility since the early 1970s (Dynan, Elmendorf, and Sichel 2012). In recent years, the perceived growth of the gig economy (Katz and Krueger 2019a) and the proliferation of "just-in-time" scheduling, where weekly schedules are updated almost constantly, have exacerbated income volatility by adding uncertainty from month to month and even week to week in schedules, total hours worked, and earnings, particularly for the working poor (Hannagan and Morduch 2015) and young adults (Lambert, Fugiel, and Henly 2014). While recent empirical research raises questions about whether there has really been a substantial increase in gig jobs nationally (Katz and Krueger 2019b), anecdotal evidence has raised concerns about the implication of gig jobs on workers. These changes in the labor market can impose challenges for workers, particularly transitionaged youth and young adults with disabilities.

These labor market changes are occurring at a time when policymakers have sharpened their focus on increasing employment rates for young adults with disabilities. The Workforce Investment Opportunities Act, signed in 2014, prioritizes employment of young adults with disabilities in competitive, integrated settings and funds the provision of pre-employment transition services to postsecondary students with disabilities through vocational rehabilitation and other workforce agencies. In addition, in recent years there have been growing political pressures to make receipt of benefits from Medicaid and other public programs contingent on work requirements.

Although the flexibility of the gig economy and the hardship created by schedule and earnings unpredictability have been documented in the popular press, little is known about how these changes have impacted individuals with disabilities. It is possible that they could lead to increases or decreases in both labor force and program participation among people with disabilities. On one hand, the proliferation of nonstandard jobs could have expanded opportunities for individuals with disabilities. If alternative work arrangements allow people with disabilities to have greater control over their work hours, this could increase labor force participation (Hurst and Pugsley 2011; Mulcahy 2016). In particular, Social Security disability beneficiaries wary of earning above the substantial gainful activity level for fear of losing their cash benefits may find nonstandard jobs attractive. In addition, the ability to telework in many such jobs eliminates the need for strenuous commutes that can include lack 
of access to appropriate transportation or travel in inclement weather. It also provides opportunities to work in environments that are most conducive to meeting disability and other health-related needs. Employers may also be more willing to hire workers with disabilities for gig jobs (rather than as regular hires) because they are taking on less risk and usually have no responsibility for health insurance.

On the other hand, it is not clear workers with disabilities benefit from such variability. The control over scheduling may be overstated, and the unpredictability and volatility of hours and earnings could prove challenging for many individuals. Workers who need accommodations for transportation or personal care at the workplace may not have access to those accommodations on demand. Furthermore, workers in gig jobs do not enjoy many of the protections of our regulatory and social insurance systems, including sick leave, paid vacation, unemployment insurance, workers compensation, and private disability insurance. They are not offered employer-provided health insurance, which could be especially important for individuals with disabilities. Previous studies have documented that temporary work is associated with worse occupational health and higher risks of workplace injuries, as well as lower rates of postinjury employment and earnings (Underhill and Quinlan 2011; Broten, Dworsky, and Powell 2019). As a result, the net effect of the growth of gig jobs and other jobs with varied work schedules on labor force participation of young adults with disabilities is ambiguous.

This paper attempts to shed light on the role of irregular schedules among young workers with disabilities. Recognizing that the most recent evidence suggests that the growth in gig jobs has been more modest than popular wisdom has perceived, we examine variations in scheduling and hours among younger workers. Although large, nationally representative surveys do not directly measure whether workers are employed in gig jobs, data on hours and schedules in the Current Population Survey (CPS) and the National Longitudinal Survey of Youth 1997 (NLSY97) over the past decade allow us to examine irregular hours that are associated with a broader set of nonstandard jobs. First, we document the magnitude of several features of irregular schedules among workers with disabilities in recent years. Second, we examine differences in irregular schedules between workers with and without disabilities. Third, we describe the trends in these features over the past decade.

Overall, the evidence shows that young adults with disabilities have higher unpredictability and volatility in their work hours than young adults without disabilities. 
Leveraging the monthly longitudinal design of the CPS, we find that young workers with disabilities have much higher individual volatility - measured by the variance and the coefficient of variation - in work hours across months. They are more likely to report that their hours varied from week to week. Results are similar from the NLSY. Young adults with disabilities are less likely to work a regular shift and more likely to report having an irregular schedule. Somewhat surprisingly, we did not observe any distinct changes in volatility in hours or reported work reschedules either for workers with or without disabilities between 2008 and 2018, providing no evidence that the growth of nonstandard jobs has increased work hour volatility among young workers with disabilities.

\section{Data and Overview of Analysis}

\section{Current Population Survey}

The CPS is a monthly U.S. household survey conducted jointly by the U.S. Census Bureau and the Bureau of Labor Statistics. A battery of labor force and demographic questions, known as the "basic monthly survey" is asked every month. Each monthly CPS has included about 140,000 individuals living in about 70,000 households. Upon selection into the CPS sample, individuals are surveyed for four consecutive months, left un-enumerated during the subsequent eight months, and then resurveyed in each of another four consecutive months; new rotation groups are brought into the CPS sample each calendar month. The CPS 4-8-4 rotating panel design guarantees that in any calendar month, about one-eighth of the sample is in its first month of enumeration (month-in-sample 1, or MIS1), about one-eighth is in its second month (month-in-sample 2, or MIS2), and so forth. We used the unique identifiers provided by the Integrated Public Use Microdata Series to link individuals longitudinally (Drew, Flood, and Warren 2014), creating an unbalanced panel dataset with each person followed over months, with a maximum of eight months of data for each individual.

We leverage the monthly longitudinal design of the CPS to examine month-to-month volatility in employment and work hours among young adults between ages 18 and 30 in years 2008 to $2018 .{ }^{1}$ We limit our analyses to these years primarily because the CPS changed how it identifies people with disabilities in 2008 , but also to capture the end of the Great Recession and

\footnotetext{
${ }^{1}$ We use unique identifiers constructed by the Integrated Public Use Microdata Series to link individuals longitudinally (Drew, Flood, and Warren 2014).
} 
recovery when alternative work arrangements grew. Whereas other longitudinal surveys provide longer panels, the CPS offers the largest sample of nationally representative young adults with consistent measures of disability and monthly employment over this time period. One limitation of using the monthly surveys is that earnings are asked only in the outgoing rotation groups (that is, when month-in-sample equals 4 or 8 ), so we are unable to directly measure volatility in earnings.

Our analysis uses CPS measures of employment and disability. Each month, respondents are asked about their employment status in the prior week and their usual hours worked, including if their hours vary. To identify people with disabilities, we use the CPS sequence of six questions related to functional and activity limitations used to identify the population with disabilities. This sequence is used to identify disability in all Census Bureau data collection products. Individuals with an affirmative response to one or more of the six questions are identified as having a disability. Four questions are related to sensory and functional limitations: deafness or serious difficulty hearing, blindness or visual impairments, difficulty walking or climbing stairs, and cognition. Two questions are related to activity limitations: self-care activities and independent living activities.

\section{National Longitudinal Survey of Youth 1997}

We also analyze data in the NLSY97 because of its focus on youth; the fact that it measures disability in a very different way, potentially capturing a more comprehensive set of young adults with disabilities; and its inclusion of additional information on scheduling. The NLSY97 is a nationally representative sample of about 9,000 individuals who were ages 12 to 16 when they were first interviewed in 1997. The study re-interviewed these individuals annually through 2012 and currently re-interviews sample members every two years. We focus on employment outcomes as reported in interviews from 2008 to 2015, when the sample members were ages 18 to 36 .

The NLSY97 offers several advantages for studying the research questions. First, the age range of sample members and the availability of longitudinal data provide information on disability that may be more comprehensive than what is captured in the CPS. Both the baseline and several follow-up surveys include detailed questions on physical and mental health conditions and disabilities. Several researchers who have used the NLSY97 to study early 
transition outcomes of youth with disabilities document that the sample size of youth with disabilities is sufficient (Shandra 2011, Mann and Honeycutt 2014), with disability of roughly 12 percent at baseline and roughly 25 percent a decade later (Mann and Honeycutt 2014). These rates may seem high, but they reflect an inclusive measure of disability, described in the next paragraph. Third, the NLSY97 directly asks respondents about irregular schedules. In each round of the NLSY97, respondents report on employment and the type of schedule (regular, irregular, shift, rotating, or other). ${ }^{2}$

In this study, we use NLSY measures of conditions and disability at the initial point of data collection and five years later (Survey Rounds 1 and 6). The data identify conditions and whether they result in functional limitations. The NLSY97 asks questions on four broad disability impairment categories: physical, chronic, sensory, and mental. When asking respondents about disability status, the interviewer first asks four questions, one about each type of impairment: (1) "Have you ever had a part of your body that was deformed or missing (e.g., tonsils)?" (physical impairment); (2) "Have you ever been diagnosed with any other chronic health condition or life threatening disease such as asthma, cardiovascular or heart condition, anemia, diabetes, cancer, epilepsy, HIV/AIDS, sexually transmitted disease other than HIV/AIDS, other?" (chronic impairment); (3) "Have you ever had trouble seeing, hearing, or speaking?" (sensory impairment); and (4) "Have you ever had an eating disorder, a learning or emotional problem, or a mental condition that has limited your ability to attend school regularly, do regular school work, or work at a job for pay?" (mental impairment). If the respondent indicates having one of these types of impairment, the interviewer follows up by asking whether the respondent has any of a list of conditions associated with that impairment and, if so, whether that condition limits the respondent's functional ability a lot, a little, or not at all. For example, for sensory impairments, conditions include vision difficulty, blindness, hearing difficulty, deafness, speech impairments, and other sensory conditions. In Round 1, parents report the youth's disability status; in Round 6, youth report their own disability status.

We create two sets of measures of disability—one set based on whether the individual reports having the condition at the time of the interview and a second narrower set based on

\footnotetext{
${ }^{2}$ Beginning in Round 15 in 2011, the survey added questions on variability in weekly hours, how far in advance the respondent learned of his or her schedule, and schedule control. Our plan to analyze these responses was not feasible when we discovered that, due to a survey skip logic error, only 26 percent of respondents were asked these questions (Lambert, Fugiel, and Henly 2014).
} 
whether the individual also reports that the condition is functionally limiting. Our preferred measures use the condition measures because reports of functional limitation may be endogenous to labor market outcomes (Waidmann, Bound, and Schoenbaum 1995; Benitez-Silva, Disney, and Jimenez-Martin 2009). ${ }^{3}$ Because the questions are asked only in certain survey years, we assume that the state of disability is absorbing - that is, once the person reports a disability, we consider them as having a disability in all subsequent waves. This assumption likely contributes to the relatively high prevalence rates in latter waves.

\section{Overview of Analysis}

Our analysis is descriptive. Using the CPS data, we first compare the mean likelihood of employment (captured in the first month they respond to the survey) between young adults with and without disabilities over time, from 2008 to 2018. We continue the analysis by examining other constructed measures of job and hours volatility. First, we compare the mean percentage of employed workers who report that their hours varied from week to week in the first month they respond to the survey, over time and by disability status. ${ }^{4}$ Second, we calculate the coefficient of variation as a measure of month-to-month volatility in work hours, which is the standard deviation of the person's hours worked last week divided by the average of the person's hours worked last week over all months the person is interviewed (up to eight months). ${ }^{5}$ Hours worked are conditional upon employment, and hence measure labor force participation at the intensive margin. To account for differences in employment rates between people with and without disabilities, we also construct a second coefficient of variation where zero hours are imputed for months when the person is unemployed. To allow for a meaningful measure of volatility, we include in the analytic sample only individuals who were interviewed at least four times.

We similarly examine employment outcomes among all sample members in the NLSY97 over the 2008 to 2016 period. We first examine employment, and among those who are working, we examine the prevalence of different types of work schedules. We compare mean

\footnotetext{
${ }^{3}$ Results using the limitation definition are qualitatively similar and available by request.

${ }^{4} \mathrm{We}$ also calculated trends in self-employment and freelancing but do not report these results (though they are available on demand), which were similar to results for related measures.

${ }^{5}$ The coefficient of variation has been used in other research examining income volatility, such as Deshpande (2016), Hannagan and Morduch (2015), and Mills and Amick (2010). The advantage of this measure is that it accounts for both the spread and difference in means.
} 
rates by disability status, to shed light on trends in employment arrangements from 2008 to 2016 among young adults with disabilities and their peers without disabilities.

\section{Results}

Table 1 contains descriptive statistics by presence of disability for the CPS and NLSY variables. We depict our key results from the CPS analysis graphically in Figures 1 to 4 . Figure 1 shows the proportion of young adults employed, captured in the first month they were interviewed. Consistent with other research, we show that the level of employment is lower among people with disabilities, compared to their counterparts without disabilities. The gap between the two lines is largest during the Great Recession years from 2008 to 2012. Employment among people with disabilities began to rise distinctly after 2014, although employment remains higher among people without disabilities in all years.

We then turn to examining measures of volatility. First, the percentage who reported that their hours varied each week was higher among young adults with disabilities. Interestingly, however, the measure exhibits a downward trend for both groups (Figure 2). Next, we find that the coefficient of variation in hours worked last week is higher among workers with disabilities, suggesting that young adults with disabilities experience higher volatility in work hours than those without disabilities. However, volatility in work hours for either group does not seem to be changing measurably in recent years (Figure 3). When we use the imputed version of hours worked last week (which imputes zero hours for months where the person is not employed), we find that the difference in work hour volatility between young adults with disabilities and those without is further magnified. Like in Figure 3, volatility measured in this way does not appear to have changed distinctly over time for either group (Figure 4). The lack of a distinct trend in both Figures 3 and 4 suggests that volatility has not changed measurably for either group over the past 10 years. ${ }^{6}$

The results from the NLSY analysis are consistent. Employment fell during the Great Recession but recovered in the years after, with employment remaining higher among young adults without disabilities compared to those with disabilities (Figure 5). A lower proportion of workers with disabilities report working regular shifts, and it appears that the proportion has in

\footnotetext{
${ }^{6}$ The one notable trend break is perhaps the drop in volatility from 2017 to 2018 . However, it is too early to know whether this is a temporary aberration or a longer-term change.
} 
fact increased in recent years for both groups (Figure 6). Similarly, a higher proportion of workers with disabilities report having an irregular work schedule than do their counterparts without disabilities, and in both groups it appears that the trend is decreasing (Figure 7). A higher proportion of workers with disabilities report that their shifts rotate from week-to-week, since 2010, and in contrast to other trends reported in this study, it appears that the share with shifts rotating from week to week has increased slightly in recent years for both groups (Figure 8). However, we caution that although the trends we observe across various measures in the NLSY may be partly due to changes in the labor market, they could also be due to the effects of "maturation" of the sample as they age and transition into more-stable career choices. Nonetheless, the evidence from the NLSY is largely consistent with that in the CPS, suggesting volatility of work hours has decreased rather than increased in recent years both for young adults with and without disabilities.

\section{Conclusion}

In this paper, we studied the prevalence of scheduling uncertainty and volatility in hours worked among young adults with disabilities using two nationally representative datasets, the Current Population Survey and the National Longitudinal Youth Survey. We present two key findings. First, although existing research has documented lower labor force participation rates and hours worked among people with disabilities, we show that young adults with disabilities are also more likely to report having irregular work schedules and experience higher volatility in their month-to-month work hours than their peers without disabilities. The higher volatility in work hours likely translates into higher income volatility, although we are not able to examine this question using the data we use. Second, we find limited evidence that the prevalence of irregular work schedules or the volatility of work hours have increased either for young adults with or without disabilities. Despite the growth of the gig economy and alternate work arrangements, the percentage of youth who report varying hours or irregular schedules appears in fact to have decreased in recent years. Although this finding in the NLSY may partly reflect maturation of the youth sample, the results following multiple cross sections of similarly aged CPS respondents are consistent with this conclusion. Similarly, we do not find any measurable changes in the volatility of hours worked in the past decade for either group. However, a key 
limitation of our study is that, due to data constraints, we are unable to identify whether a person works in a gig economy job.

In some respects, the increased availability of gig jobs might make it easier for adults with disabilities to work. They may find more part-time opportunities, including opportunities to work without losing their public disability and health benefits. To the extent this is true, an increase in gig jobs could lead to higher employment rates among workers with disabilities. However, the day-to-day unpredictability in these jobs could present different challenges to workers, especially workers who need accommodations. Although the results in this study do not provide evidence of increased hours volatility on average across workers, future research with improved data on job categorization could explore more directly the potential benefits and risks of gig economy jobs for people with disabilities. 


\section{References}

Benitez-Silva, Hugo, Richard Disney, and Sergi Jimenez-Martin. 2009. "Disability, Capacity for Work, and the Business Cycle: An International Perspective." State University of New York at Stonybrook. Unpublished Mimeo.

Broten, Nicholas, Michael Dworsky, and David Powell. 2019. "How Do Alternative Work Arrangements Affect Income Risk After Workplace Injury?” Working Paper 25989. Cambridge, MA: National Bureau of Economic Research.

Deshpande, M. 2016. "The Effect of Disability Payments on Household Earnings and Income: Evidence from the SSI Children's Program. Review of Economics and Statistics 98(4): 638654.

Dynan, Karen, Douglas Elmendorf, and Daniel Sichel. 2012. "The Evolution of Household Income Volatility." B.E. Journal of Economic Analysis and Policy 12(2): 1-40.

Hannagan, Anthony, and Jonathan Morduch. 2015. "Income Gains and Month-to-Month Income Volatility: Household Evidence from the US Financial Diaries.” NYU Wagner Research Paper No. 2659883. New York, NY.

Hurst, Erik, and Benjamin Wild Pugsley. 2011. "What Do Small Businesses Do?" In Brookings Papers on Economic Activity, edited by David H. Romer and Justin Wolfers, 73-118. Washington DC: Brookings Institution Press.

Katz, Lawrence F. and Alan B. Krueger. 2019a. "The Rise and Nature of Alternative Work Arrangements in the United States, 1995-2015." ILR Review 72(2): 382-416.

Katz, Lawrence F. and Alan B. Krueger. 2019b. "Understanding Trends in Alternative Work Arrangements in the United States." Working Paper 25425. Cambridge, MA: National Bureau of Economic Research.

Lambert, Susan J., Peter J. Fugiel, and Julia R. Henly. 2014. "Precarious Work Schedules Among Early-Career Employees in the US: A National Snapshot." Employment, Instability, Family Well-being, and Social Policy Network Issue Brief. Chicago, IL: University of Chicago.

Mann, David R., and Todd Honeycutt. 2014. "Is Timing Everything? Disability Onset of Youth and Their Outcomes as Young Adults." Journal of Disability Policy Studies 25(2): 117-129.

Mills, Gregory, and Joe Amick. 2010. "Can Savings Help Overcome Income Instability?" Perspectives on Low-Income Working Families Brief 18. Washington, DC: Urban Institute.

Mulcahy, Diane. 2016. "Who Wins in the Gig Economy, and Who Loses." Harvard Business Review, October 27. Available at https://hbr.org/2016/10/who-wins-in-the-gig-economyand-who-loses 
Rivera Drew, J. A., Flood, S., \& Warren, J. R. 2014. Making Full Use of the Longitudinal Design of the Current Population Survey: Methods for Linking Records across 16 Months. Journal of Economic and Social Measurement 39(3): 121-144.

Shandra, Carrie L. 2011. "Life Course Transitions among Adolescents with and Without Disabilities: A Longitudinal Examination of Expectations and Outcomes." International Journal of Sociology 41(1): 67-86.

Underhill, Elsa M., and Michael G. Quinlan. 2011. "How Precarious Employment Affects Health and Safety at Work: The Case of Temporary Agency Workers". Relations Industrielles 66(3): 397-421.

Waidmann, Timothy, John Bound, and Michael Schoenbaum. 1995. "The Illusion of Failure: Trends in the Self-Reported Health of the U.S. Elderly." Milbank Quarterly 73(2): 25388. 
Table 1. Summary Statistics of Key Variables

Panel A. CPS Monthly Surveys, 2018-2018

\begin{tabular}{|c|c|c|c|}
\hline Variable & $\begin{array}{c}\text { Any } \\
\text { disability }\end{array}$ & $\begin{array}{c}\text { No } \\
\text { disability }\end{array}$ & Overall \\
\hline Any disability $(\%)$ & 100.0 & 0.0 & 0.05 \\
\hline Hearing difficulty & 15.6 & 0.0 & 0.8 \\
\hline Vision difficulty & 14.3 & 0.0 & 0.7 \\
\hline Difficulty remembering $^{\text {a }}$ & 62.5 & 0.0 & 3.2 \\
\hline Physical difficulty ${ }^{b}$ & 25.0 & 0.0 & 1.3 \\
\hline Independent living limitation ${ }^{\mathrm{c}}$ & 34.9 & 0.0 & 1.8 \\
\hline Personal care limitation ${ }^{d}$ & 12.5 & 0.0 & 0.6 \\
\hline In labor force $(\%)$ & 49.8 & 75.6 & 74.3 \\
\hline Employed (\%) & 78.4 & 90.0 & 89.6 \\
\hline Hours vary $^{\mathrm{e}}(\%)$ & 10.1 & 7.8 & 7.9 \\
\hline Hours worked ${ }^{\mathrm{e}}$ & 32.9 & 36.4 & 36.3 \\
\hline Hours worked, imputed ${ }^{f}$ & 12.4 & 24.5 & 23.9 \\
\hline $\begin{array}{l}\text { Coefficient of variation, hours } \\
\text { worked }^{\mathrm{e}}\end{array}$ & 0.25 & 0.19 & 0.19 \\
\hline $\begin{array}{l}\text { Coefficient of variation, hours } \\
\text { worked, imputed }\end{array}$ & 0.53 & 0.52 & 0.81 \\
\hline Age & 23.8 & 23.7 & 23.7 \\
\hline
\end{tabular}

Panel B. NLSY data, 2018-2015

\begin{tabular}{|c|c|c|c|}
\hline Variable & $\begin{array}{c}\text { Any } \\
\text { disability }\end{array}$ & $\begin{array}{c}\text { No } \\
\text { disability }\end{array}$ & Overall \\
\hline Any disability (\%) & 100.0 & 0.0 & 52.9 \\
\hline Mental & 31.9 & 0.0 & 16.4 \\
\hline Sensory & 54.3 & 0.0 & 28.1 \\
\hline Physical & 6.6 & 0.0 & 3.4 \\
\hline Chronic & 53.6 & 0.0 & 27.9 \\
\hline Working $(\%)$ & 84.0 & 87.4 & 85.6 \\
\hline Regular shift ${ }^{\mathrm{a}}(\%)$ & 80.3 & 77.4 & 78.8 \\
\hline Shift rotates ${ }^{\mathrm{a}}(\%)$ & 10.8 & 10.6 & 10.7 \\
\hline Irregular schedule $(\%)$ & 6.6 & 4.8 & 5.8 \\
\hline Other schedule $^{\mathrm{a}}(\%)$ & 5.2 & 4.3 & 4.8 \\
\hline Age & 28.9 & 28.7 & 28.8 \\
\hline
\end{tabular}


${ }^{\mathrm{d}}$ Indicates whether respondents have any physical or mental health condition that has lasted at least 6 months and makes it difficult for them to take care of their own personal needs, such as bathing, dressing, or getting around inside the home.

${ }^{\mathrm{e}}$ Defined only for those who are employed in that month.

${ }^{\mathrm{f}}$ Zero hours are imputed for months where the person was unemployed.

Note. Number of person-month observations in Panel A is 2,353,170. Total number of person-year observations in Panel B is 49,283. 
Figure 1. Employment among Young Adults with and without Disabilities, CPS 2008-2018

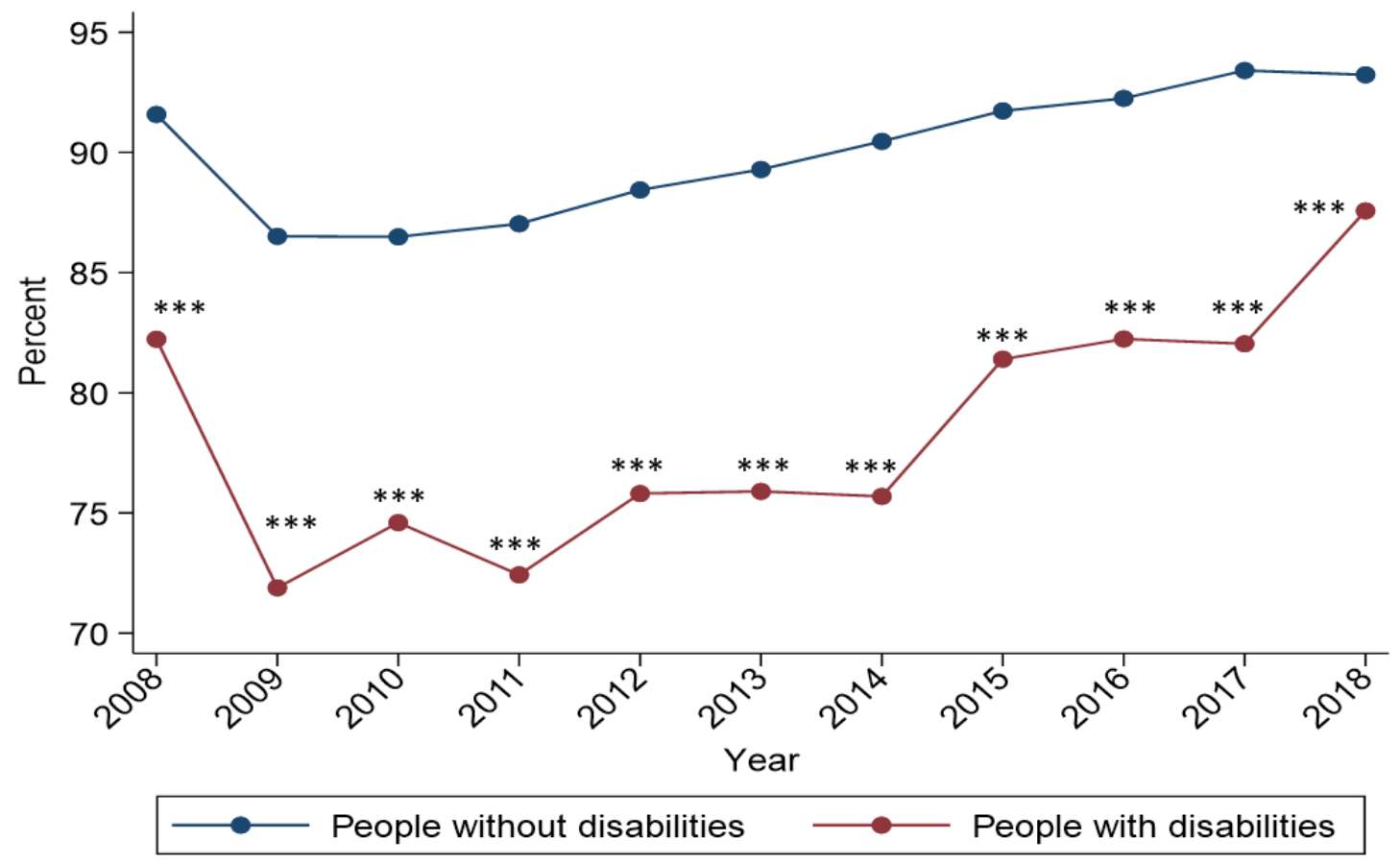

$* / * * / * * *$ indicates that the difference in means across the two groups is significantly different from zero at the $0.10 / 0.05 / 0.01$ level based on a two-tailed test.

Figure 2. Percentage of Workers Having Varying Hours among Young Adults with and without Disabilities, CPS 2008-2018

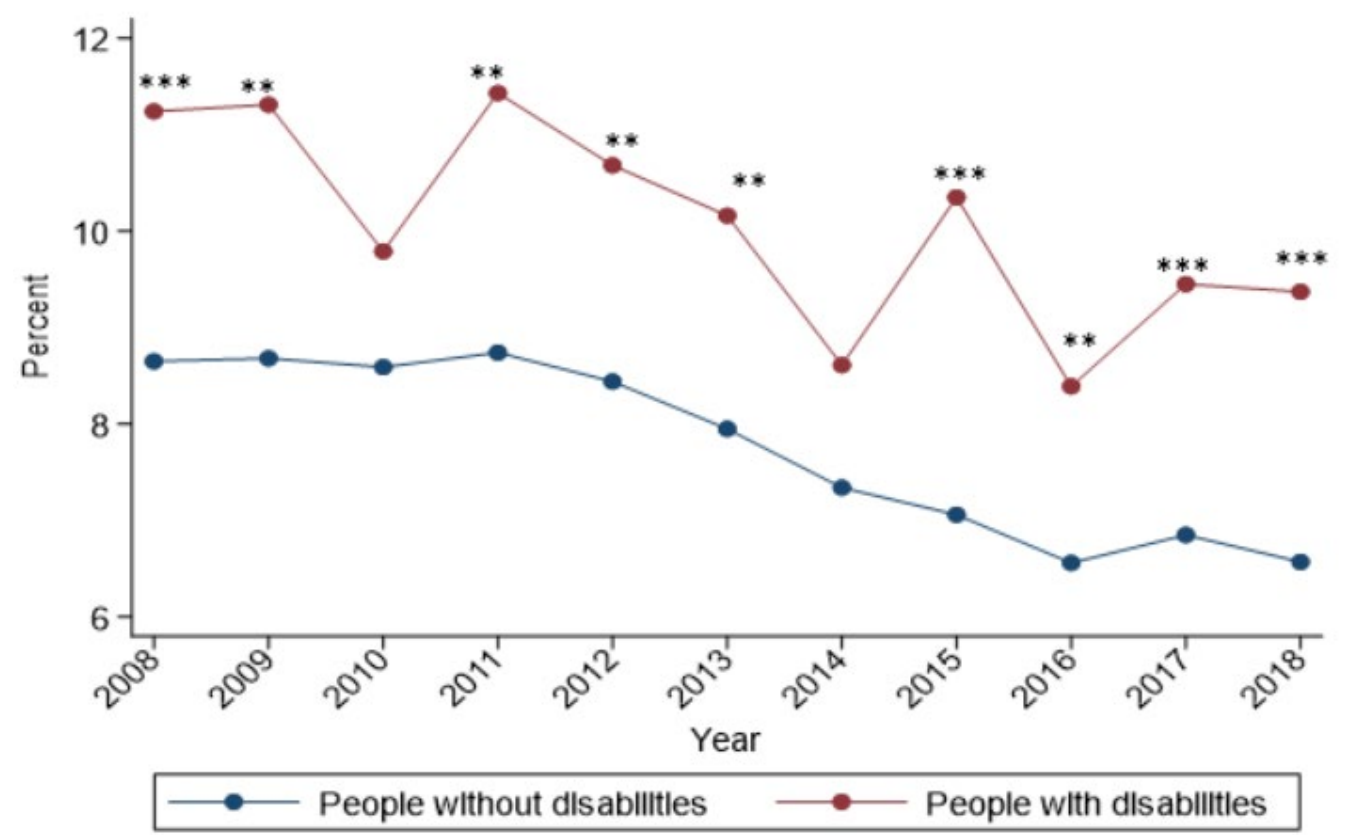

$* / * * / * * *$ indicates that the difference in means across the two groups is significantly different from zero at the $0.10 / 0.05 / 0.01$ level based on a two-tailed test. 
Figure 3. Coefficient of Variation of Hours Worked among Young Adults with and without Disabilities, CPS 2008-2018

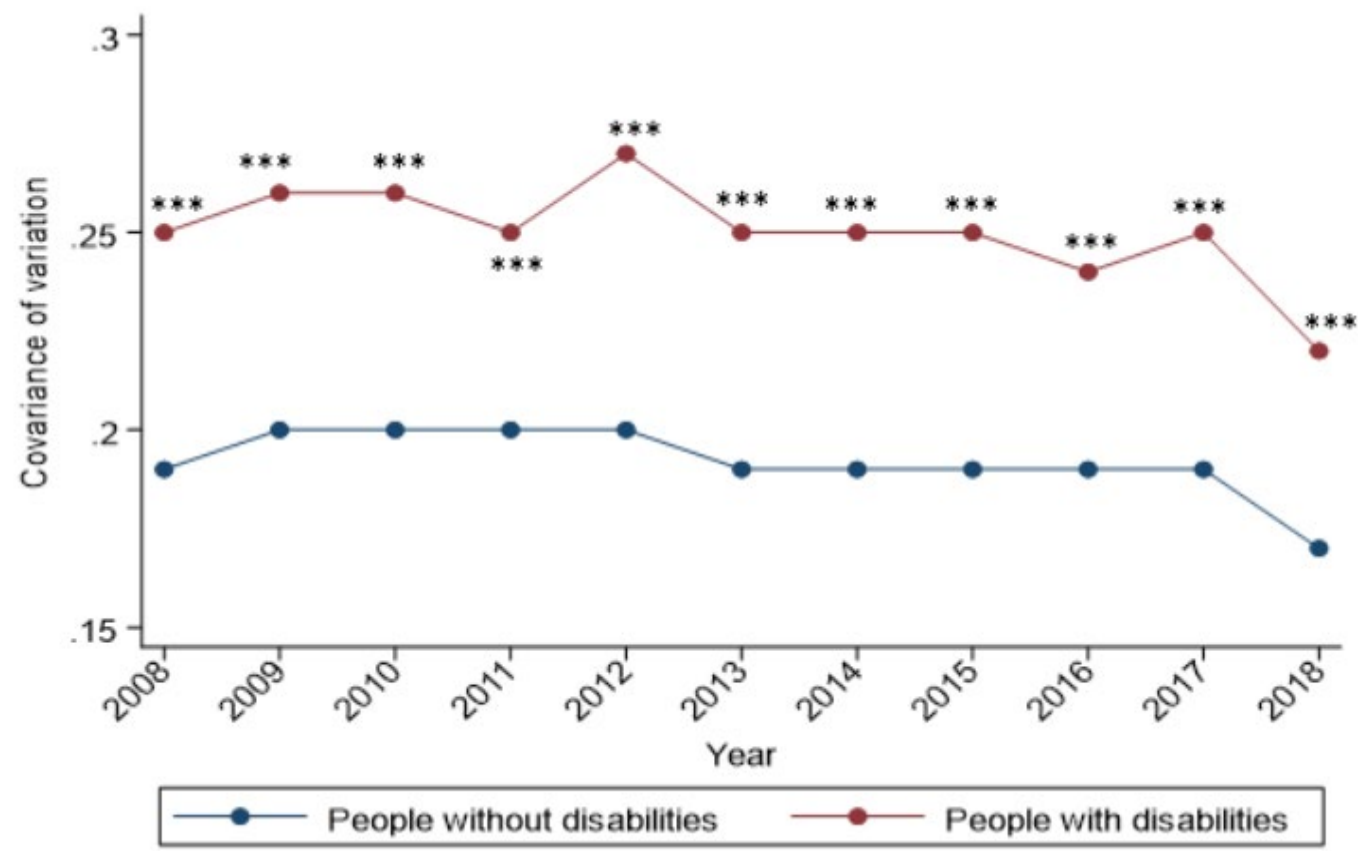

$* / * * / * * *$ indicates that the difference in means across the two groups is significantly different from zero at the $0.10 / 0.05 / 0.01$ level based on a two-tailed test.

Figure 4. Coefficient of Variation of Imputed Hours Worked among Young Adults with and without Disabilities, CPS 2008-2018

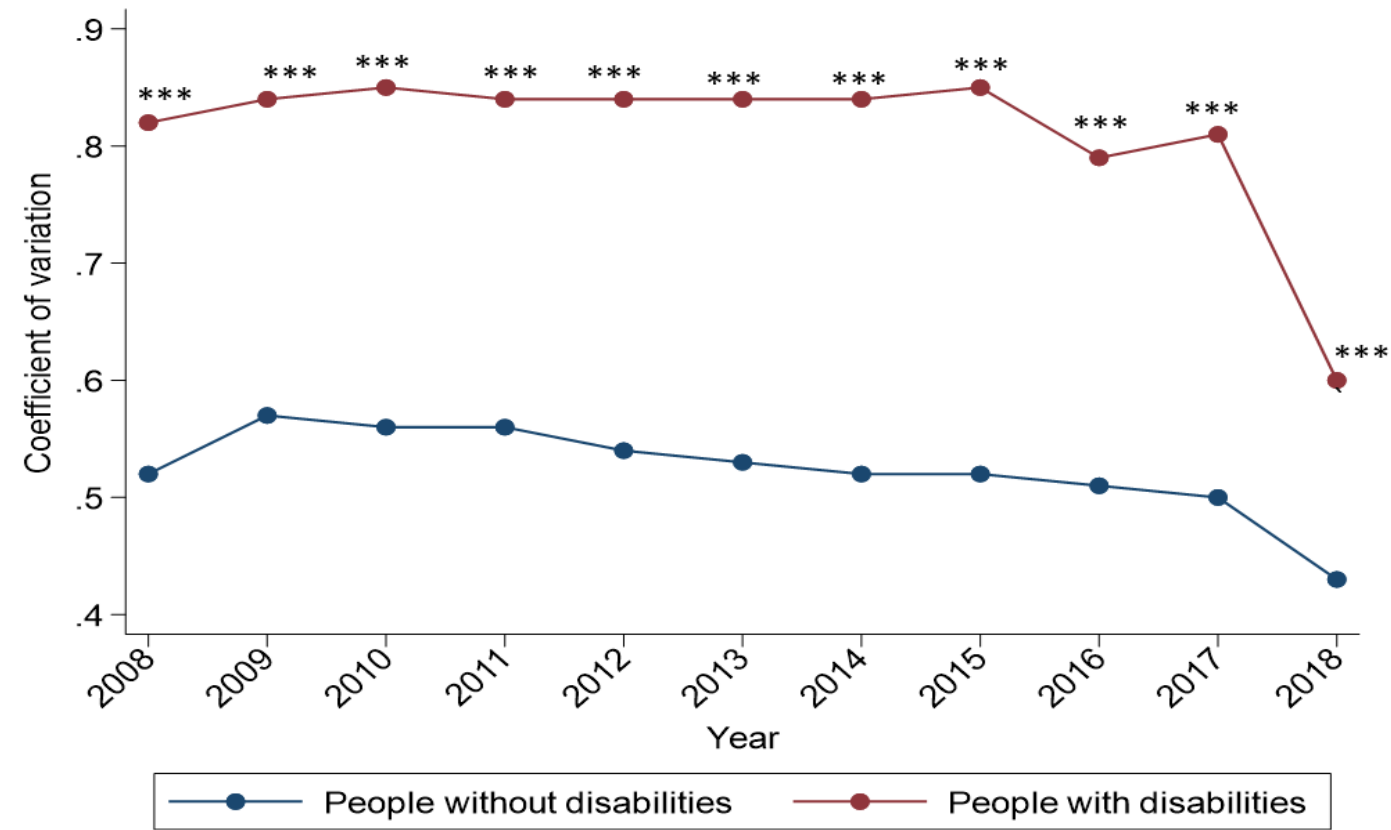

$* / * * / * * *$ indicates that the difference in means across the two groups is significantly different from zero at the $0.10 / 0.05 / 0.01$ level based on a two-tailed test. 
Figure 5. Employment among Young Adults with and without Disabilities, NLSY 2008-2015

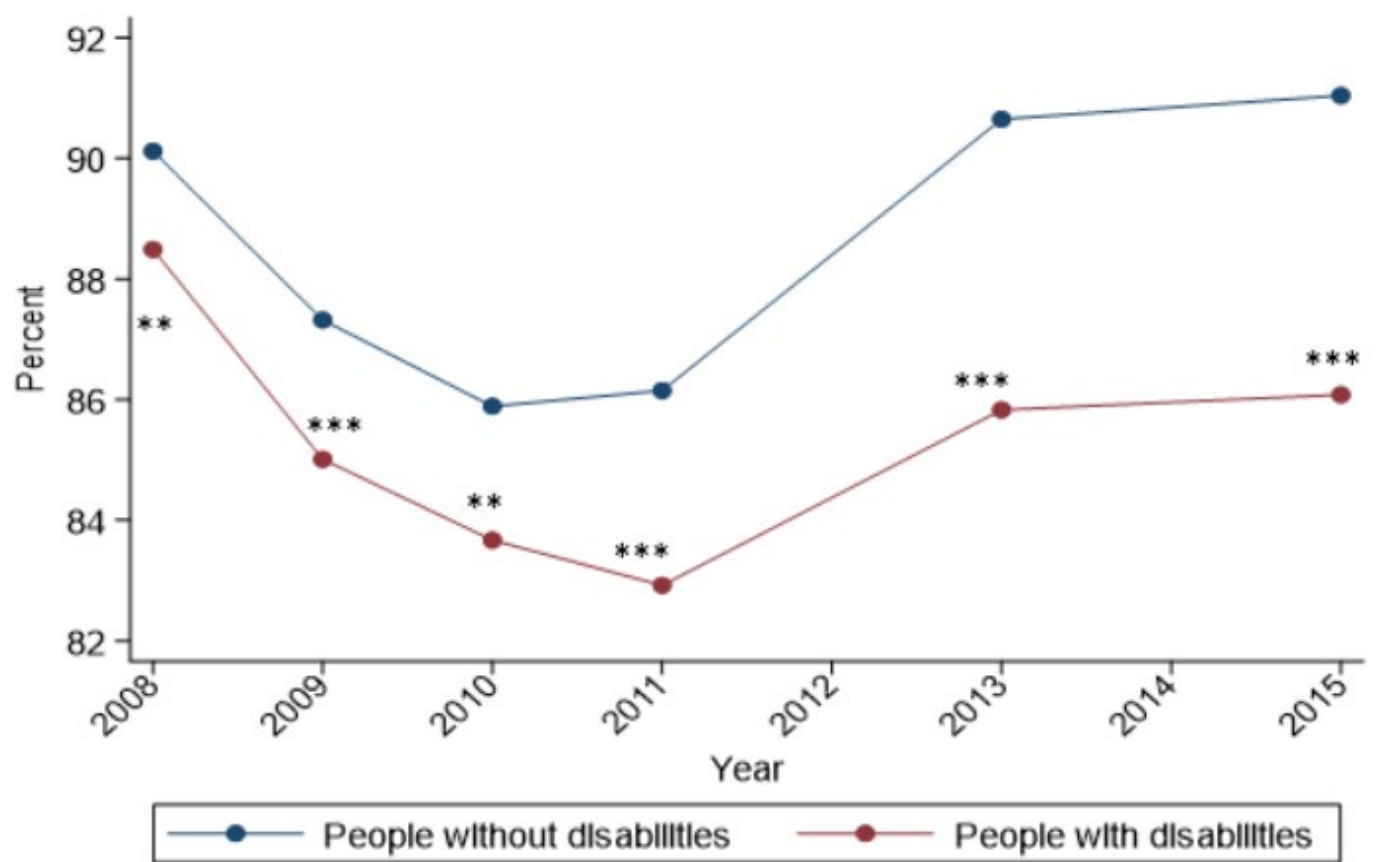

$* / * * / * * *$ indicates that the difference in means across the two groups is significantly different from zero at the $0.10 / 0.05 / 0.01$ level based on a two-tailed test.

Figure 6. Percentage Reporting Working Regular Shifts among Young Adults with and without Disabilities, NLSY 2008-2015

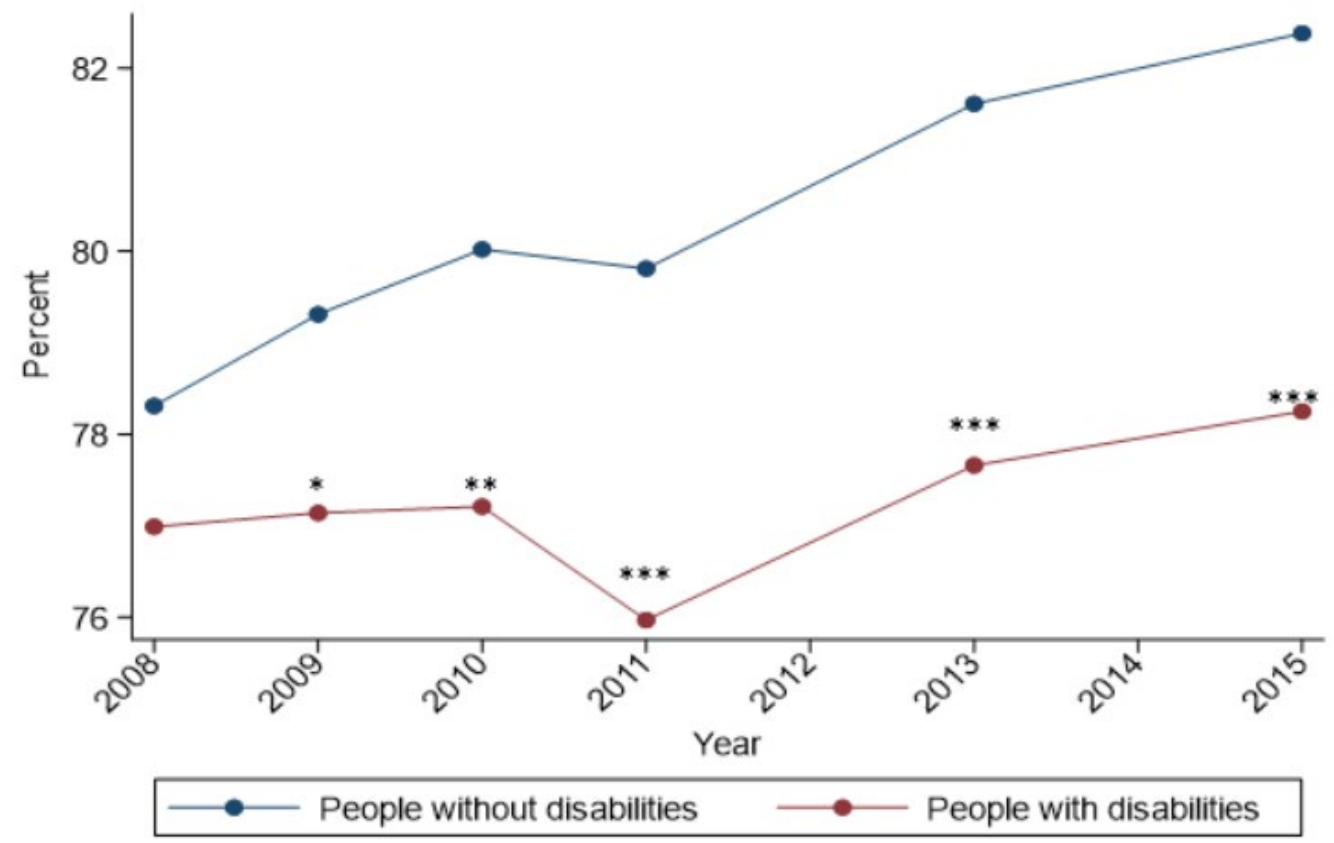

$* / * * * * *$ indicates that the difference in means across the two groups is significantly different from zero at the $0.10 / 0.05 / 0.01$ level based on a two-tailed test. 
Figure 7. Percentage Reporting Having Irregular Work Schedules among Young Adults with and without Disabilities, NLSY 2008-2015

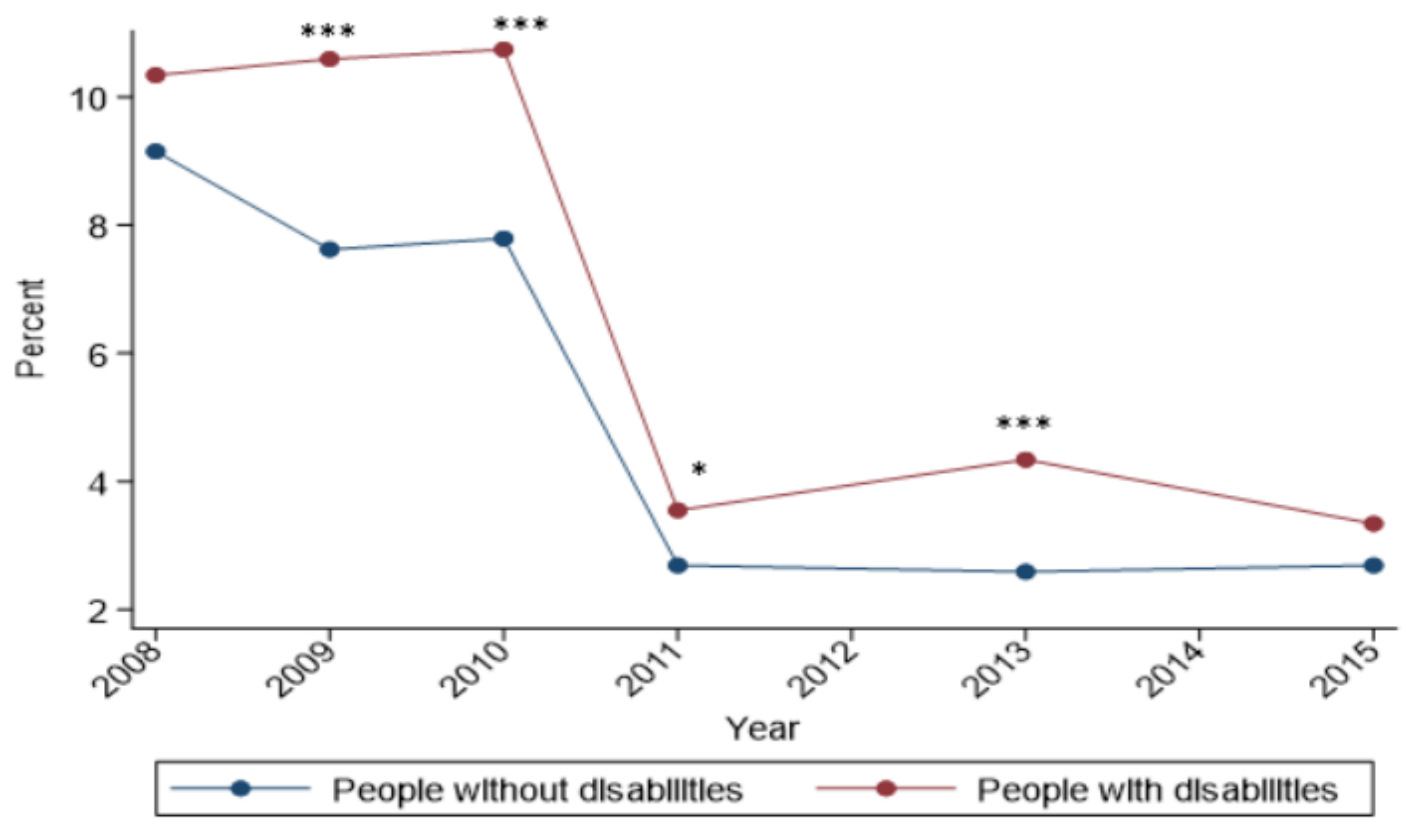

$* / * * / * * *$ indicates that the difference in means across the two groups is significantly different from zero at the $0.10 / 0.05 / 0.01$ level based on a two-tailed test.

Figure 8. Percentage Reporting Having Rotating Work Shifts among Young Adults with and without Disabilities, NLSY 2008-2015

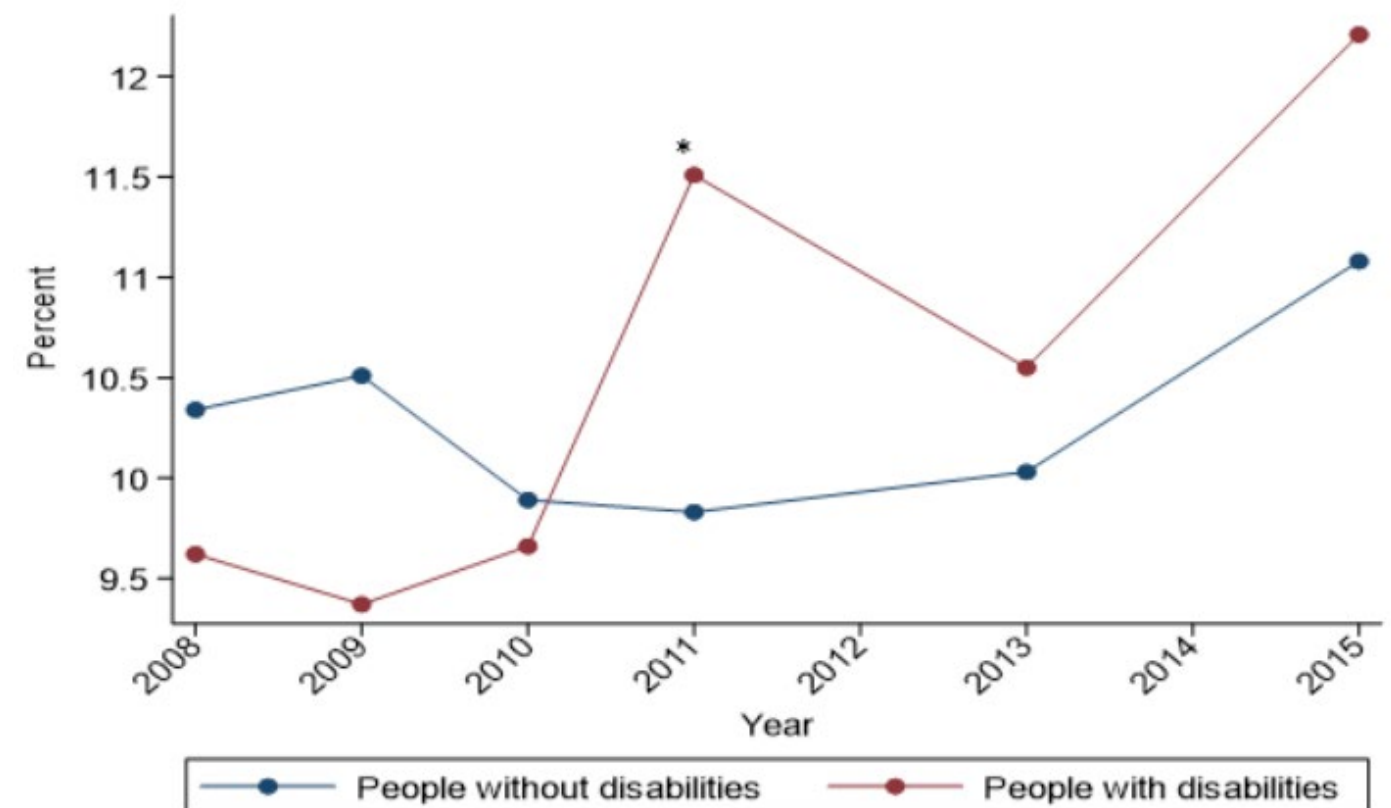

$* / * * / * * *$ indicates that the difference in means across the two groups is significantly different from zero at the $0.10 / 0.05 / 0.01$ level based on a two-tailed test. 


\section{RECENT WORKING PAPERS FROM THE CENTER FOR RETIREMENT RESEARCH AT BOSTON COLLEGE}

Wages and the Value of Nonemployment

Simon Jäger, Benjamin Schoefer, Samuel Young, and Josef Zweimüller

The Equilibrium and Spillover Effects of Early Retirement

Simon Jäger, Benjamin Schoefer, and Josef Zweimüller, January 2020

Measuring Racial/Ethnic Retirement Wealth Inequality

Wenliang Hou and Geoffrey T. Sanzenbacher, January 2020

A Study of Longitudinal Trajectories of Health and Job Demand on Retirement Age Amal Harrati and David Rehkopf, January 2020

Participation and Pre-Retirement Withdrawals in Oregon's Auto-IRA

Laura D. Quinby, Alicia H. Munnell, Wenliang Hou, Anek Belbase, and Geoffrey T.

Sanzenbacher, November 2019

Why Are 401(k)/IRA Balances Substantially Below Potential?

Andrew G. Biggs, Alicia H. Munnell, and Anqi Chen, November 2019

How Best to Annuitize Defined Contribution Assets?

Alicia H. Munnell, Gal Wettstein, and Wenliang Hou, October 2019

How Do Older Workers Use Nontraditional Jobs?

Alicia H. Munnell, Geoffrey T. Sanzenbacher, and Abigail N. Walters, October 2019

Will More Workers Have Nontraditional Jobs as Globalization and Automation Spread? Matthew S. Rutledge, Gal Wettstein, and Sara Ellen King, July 2019

Do States Adjust Medicaid Enrollment in Response to Capitation Rates? Evidence from the Medicare Part D Clawback

Laura D. Quinby and Gal Wettstein, June 2019

The Effect of Medicare Part D on Evergreening, Generic Entry, and Drug Prices Geoffrey T. Sanzenbacher and Gal Wettstein, May 2019

Is the Drop in Fertility Due to The Great Recession or a Permanent Change?

Alicia H. Munnell, Anqi Chen, and Geoffrey T. Sanzenbacher, March 2019

Will Fewer Children Boost Demand for Formal Caregiving?

Gal Wettstein and Alice Zulkarnain, March 2019

All working papers are available on the Center for Retirement Research website

(https://crr.bc.edu) and can be requested by e-mail (crr@bc.edu) or phone (617-552-1762). 